\title{
Swabs and swab-transport media kits in the isolation of upper respiratory bacteria
}

\author{
PW ROSS, CG CUMMING, H LOUGH \\ From the Departments of Bacteriology and Oral Medicine and Pathology, University of Edinburgh, \\ EH8 $9 A G$
}

SUMMARY The recovery of upper respiratory tract bacteria on laboratory media from a variety of swabs and swab-transport media kits was examined. Organisms studied included strains of Streptococcus pyogenes, Streptococcus pneumoniae, Staphylococcus aureus, Neisseria meningitidis and Haemophilus influenzae. Although a wide range of results was obtained with regard to variables such as the type of swab or swab-transport media kit used, the time of plating, the temperature of storage of swabs and swab-transport media kits, and the nature of the suspension of the organisms, it was generally noted that recovery of organisms was better from swabs held in their plastic containers prior to plating than from swabs held in transport medium.

It has been known for some time that swabs can produce varying and occasionally misleading results when used for diagnostic purposes, particularly in epidemiological surveys. In assessment of carrier rates in epidemiological studies-for example, carriage of beta-haemolytic streptococci in the throat, it is known that swabs may produce negative results even when there are organisms in situ.

In former years, various factors made it necessary to interpret results from swabs with a degree of caution. Pollock ${ }^{1}$ reported that cotton-wool contained unsaturated fatty acids that had an antibacterial action and Mair and McSwiggan² stated that swabs sterilised by gamma radiation were bactericidal. Over the years, other factors relating to swabs have been recognised as being inimical to bacterial survival-namely desiccation in transit, the presence or absence of moisture ${ }^{3}$ and the type of swab used. 45

Various suggestions have been put forward to minimise the uncertainties of results from swabs, and these include dipping the cotton in serum, ${ }^{3}$ or albumen, ${ }^{4}$ using material other than cotton-wool, such as dacron ${ }^{6}$ or calcium alginate, ${ }^{7}$ on the swab tips, or using transport media (TM) into which swabs are placed in transit to the laboratory. ${ }^{8-10}$

Recent studies have examined the survival of potential upper respiratory tract pathogens on cotton-wool swabs; ${ }^{11}$ plain, buffered cotton-wool swabs and albumen-coated cotton-wool swabs were

Accepted for publication 30 June 1981 tested for the survival of Streptococcus pneumoniae, Staphylococcus aureus, Haemophilus influenzae, corynebacteria and Escherichia coli. Both types of swab performed equally well. Other studies have evaluated bacteriological swabs in TM in the recovery of group B streptococci. These studies showed that fewer organisms were recovered from swabs held in TM than from those held in their plastic containers. ${ }^{12}$

In the light of these findings it was decided to evaluate the various swabs and swab-TM kits available commercially in the United Kingdom for the recovery of potentially pathogenic bacteria that inhabit the upper respiratory tract. In addition to the use of commercial varieties, three swab-TM kits prepared in the local laboratory were tested.

\section{Material and methods}

SWABS

These were held either in their plastic containers or in TM. Four commercial varieties held in their containers were examined. These included plain, buffered, absorbent cotton-wool; albumen-coated cotton-wool; charcoal-coated cotton-wool; and dacron.

Swab-TM kits were either obtained commercially or prepared in the laboratory. Commercial varieties comprised cotton-wool in Amies'; cotton-wool in charcoal Amies'; and dacron in charcoal Amies'. Those prepared locally included cotton-wool in Pike's; cotton-wool in Stuart's; and cotton-wool in silica gel. 
ORGANISMS

Representative strains of the following were used: Streptococcus pyogenes, Streptococcus pneumoniae, Staphylococcus aureus, Neisseria meningitidis and Haemophilus influenzae. Stock strains and freshly isolated organisms were used.

All four varieties of swabs not held in TM were loaded with one drop $(0.02 \mathrm{ml})$ of a dilution of an overnight culture of each of the above series of organisms, mixed with either $0.08 \mathrm{ml}$ pasteurised saliva or $0.08 \mathrm{ml}$ saline. The swabs contained in the six varieties of swab-TM kits were similarly inoculated; this ensured that all swabs contained the same number of bacteria. The number loaded on to the swabs was calculated by performing surface-viable counts from $1 / 1000-1 / 100000$ dilutions of broth cultures of the organisms.

Once inoculated, swabs were held either in their plastic containers or in TM for up to $48 \mathrm{~h}$. Some were held at room temperature and an equal number at $4^{\circ} \mathrm{C}$. A first series of swabs (not held in TM) was plated out immediately after inoculation (0 hours). Eight hours after inoculation, a second series of swabs was streaked on to $5-10 \%$ human blood agar plates which were then incubated at $37^{\circ} \mathrm{C}$. A further series of swabs was then plated out at $24 \mathrm{~h}$ and a final series at $48 \mathrm{~h}$. Each series contained the same number of swabs and swab-TM kits and the same number of organisms from the five genera tested. Equal numbers of each series were examined at both temperatures, suspended in saliva or saline.

The percentage recovery refers to the number of organisms obtained after overnight incubation compared with the number in the original inoculum, using surface-viable counts. It does not refer to the percentage of swabs that were positive or negative.

\section{STATISTICAL METHODS}

Data were combined and analysed as a randomised block experiment to evaluate the effects of type of swab, TM kits, time, temperature and nature of suspension. Twice the standard error represented a significant difference.

\section{Results}

The percentage recovery of organisms from the four types of swabs varied little from swab to swab at 0 hours; in most cases, there was a difference of only around $4 \%$ in the recovery of the original inoculum. The highest and lowest recovery was obtained with $N$ meningitidis; the dacron swab gave a $13 \%$ recovery, whereas with the plain cotton-wool swab this was only $2 \%$. None of the swabs produced a recovery rate of greater than $9 \%$ with any of the organisms.

Table 1 shows the percentage recovery of Strep pyogenes at the various time intervals after 0 hours and temperatures of storage, depending on whether the organisms were suspended in saliva or saline. (Figures in parentheses relate to swabs processed in saliva.) Counts were generally higher from swabs that were not held in TM. Multiplication of the streptococci occurred at room temperature but not at $4^{\circ} \mathrm{C}$. The recovery of organisms from swabs held in silica was particularly low $(<1 \%)$ and this was observed also with other organisms.

In the recovery of Strep pneumoniae, once again swabs not held in TM produced a higher recovery rate than those immersed in TM (Table 2) and those processed in saliva gave a higher level of recovery than those mixed with saline. Not only did TM give a low recovery initially, but counts fell off more quickly as the time interval increased prior to

Table 1 Effect of time and temperature on percentage recovery of Strep pyogenes from swabs (a) held in transport media, (b) not held in transport media

\begin{tabular}{|c|c|c|c|c|c|c|}
\hline \multirow[t]{2}{*}{ Swabs } & \multicolumn{2}{|l|}{8 hours } & \multicolumn{2}{|l|}{24 hours } & \multicolumn{2}{|l|}{48 hours } \\
\hline & Room temp & $4^{\circ} \mathrm{C}$ & Room temp & $4^{\circ} \mathrm{C}$ & Room temp & $4^{\circ} \mathrm{C}$ \\
\hline \multicolumn{7}{|l|}{ Swabs held in $T M$} \\
\hline Cotton-wool in Amies' & $3(6)$ & $3(6)$ & $1(6)$ & $2(2)$ & $0(1)$ & $2(2)$ \\
\hline Cotton-wool in charcoal Amies' & $3(8)$ & $4(7)$ & $1(4)$ & $4(5)$ & $2(14)$ & $1(8)$ \\
\hline Dacron in charcoal Amies' & $6(53)$ & 4 (11) & $5(21)$ & $4(8)$ & 5 (13) & $4(9)$ \\
\hline Cotton-wool in Pike's & $7(4)$ & $1(3)$ & $4(1)$ & $2(4)$ & $8(1)$ & $3(3)$ \\
\hline Cotton-wool in Stuart's & $9(10)$ & $4(5)$ & $13(24)$ & 3 (5) & $28(26)$ & 4 (3) \\
\hline Cotton-wool in silica gel & \multicolumn{6}{|c|}{ All $<1 \%$ at all times and temperatures. } \\
\hline \multicolumn{7}{|l|}{ Swabs not held in $T M$} \\
\hline Plain & $8(10)$ & $9(7)$ & $12(23)$ & $7(9)$ & $3(3)$ & $4(7)$ \\
\hline Albumen & $24(4)$ & $5(5)$ & TNC (5) & $9(6)$ & TNC (TNC) & $6(5)$ \\
\hline Charcoal & $8(4)$ & $8(6)$ & 7 (TNC) & $10(7)$ & $1(47)$ & 4 (2) \\
\hline Dacron & $5(6)$ & $5(3)$ & TNC (TNC) & $3(4)$ & TNC (TNC) & $5(3)$ \\
\hline
\end{tabular}

TNC $=$ Too numerous to count.

NB. Results from swabs containing organisms in saline are not in parentheses. Those from organisms suspended in saliva are inside parentheses. 
Table 2 Effect of time and temperature on percentage recovery of Strep pneumoniae from swabs (a) held in transport media, (b) not held in transport media

\begin{tabular}{|c|c|c|c|c|c|c|}
\hline \multirow[t]{2}{*}{ Swabs } & \multicolumn{2}{|l|}{8 hours } & \multicolumn{2}{|l|}{24 hours } & \multicolumn{2}{|l|}{48 hours } \\
\hline & Room temp & $4^{\circ} \mathrm{C}$ & Room temp & $4^{\circ} \mathrm{C}$ & Room temp & $4^{\circ} \mathrm{C}$ \\
\hline \multicolumn{7}{|l|}{ Swabs held in $T M$} \\
\hline Cotton-wool in Amies' & $1(3)$ & $1(3)$ & $0(1)$ & $0(2)$ & $0(0)$ & $0(0)$ \\
\hline Cotton-wool in charcoal Amies' & $1(1)$ & $1(3)$ & $0(0)$ & $0(1)$ & $0(0)$ & $0(1)$ \\
\hline Dacron in charcoal Amies' & $3(4)$ & $3(5)$ & $1(2)$ & $2(3)$ & $0(1)$ & $2(2)$ \\
\hline Cotton-wool in Pike's & $1(1)$ & $2(1)$ & $1(1)$ & $1(1)$ & $0(0)$ & $0(1)$ \\
\hline Cotton-wool in Stuart's & $1(2)$ & $2(3)$ & 1 (1) & $1(3)$ & $0(0)$ & $1(2)$ \\
\hline Cotton-wool in silica gel & \multicolumn{6}{|c|}{ All $<1 \%$ at all times and temperatures. } \\
\hline \multicolumn{7}{|l|}{ Swabs not held in TM } \\
\hline Plain & $1(3)$ & $2(6)$ & $1(1)$ & $3(4)$ & $0(0)$ & $1(4)$ \\
\hline Albumen & $2(8)$ & $3(14)$ & $0(2)$ & $0(8)$ & $0(4)$ & $0(6)$ \\
\hline Charcoal & $3(8)$ & 5 (19) & $0(4)$ & 1 (17) & $0(0)$ & $0(9)$ \\
\hline Dacron & $3(10)$ & $6(10)$ & $1(2)$ & $5(5)$ & $1(0)$ & $3(10)$ \\
\hline
\end{tabular}

plating out. (" 0 " includes counts of less than $0.25 \%$ of the original inoculum as well as no growth, in all experiments of the series.)

TM produced more satisfactory results with Staph aureus (Table 3) and dacron in charcoal Amies' and cotton-wool in Stuart's gave the highest recovery rates of the TM series.

Recovery of $N$ meningitidis was generally poor, both from swabs held in TM and those held in plastic containers (Table 4) and a similar picture was obtained with $H$ influenzae (Table 5).

\section{Discussion}

It is not possible to reproduce results and figures totally accurately and faithfully in studies with swabs because of variables such as the size of the swab head, the distribution of the inoculum on the swab, the method of plating out in the laboratory, and the strains of bacteria used in the tests. Technique of swabbing in vivo will also influence the numbers of organisms on swabs. ${ }^{13}$ Nevertheless, certain trends are apparent and generalisations can therefore be made. For example, it has been shown that there is a consistent loss of around $90 \%$ of the inoculum even when swabs are plated out immediately on to media. ${ }^{514}$ The present study confirms such findings; all five different genera of bacteria exhibited much the same degree of loss when plated out.

Swabs held in their plastic containers behaved similarly in most cases, though dacron swabs were more effective in the recovery of $N$ meningitidis. Fewer bacteria were recovered from swabs held in TM than from those held in plastic containers, the exception being dacron in charcoal Amies'.

No swab or swab-TM kit sustained a satisfactory number of Haemophilus or Neisseria. This could be accounted for by fragility of the strains tested.

In most cases, strains processed in saliva showed a greater degree of recovery than those suspended in saline. Swabs held in their plastic containers containing a saliva suspension of organisms produced higher counts than those suspended in saline

Table 3 Effect of time and temperature on percentage recovery of Staph aureus from swabs (a) held in transport mediu, (b) not held in transport media

\begin{tabular}{|c|c|c|c|c|c|c|}
\hline \multirow[t]{2}{*}{ Swabs } & \multicolumn{2}{|l|}{8 hours } & \multicolumn{2}{|l|}{24 hours } & \multicolumn{2}{|l|}{48 hours } \\
\hline & Room temp & $4^{\circ} \mathrm{C}$ & Room temp & $4^{\circ} \mathrm{C}$ & Room temp & $4^{\circ} \mathrm{C}$ \\
\hline \multicolumn{7}{|l|}{ Swabs held in TM } \\
\hline Cotton-wool in Amies' & $2(2)$ & $2(4)$ & $1(1)$ & $2(6)$ & $1(1)$ & $2(3)$ \\
\hline Cotton-wool in charcoal Amies' & $3(4)$ & $2(5)$ & $2(4)$ & $3(3)$ & $2(4)$ & $2(4)$ \\
\hline Dacron in charcoal Amies' & $10(13)$ & $10(10)$ & $8(8)$ & $7(10)$ & $12(7)$ & $11(9)$ \\
\hline Cotton-wool in Pike's & $2(3)$ & $3(4)$ & $3(2)$ & $3(4)$ & 2 (2) & $4(4)$ \\
\hline Cotton-wool in Stuart's & $7(8)$ & $3(4)$ & $8(26)$ & $4(4)$ & $10(19)$ & $3(4)$ \\
\hline Cotton-wool in silica gel & $2(2)$ & $2(3)$ & $1(2)$ & $3(2)$ & $1(2)$ & $2(3)$ \\
\hline \multicolumn{7}{|l|}{ Swabs not held in $T M$} \\
\hline Plain & $4(8)$ & $6(8)$ & $9(5)$ & $5(7)$ & $2(6)$ & $4(6)$ \\
\hline Albumen & $6(6)$ & $5(8)$ & $7(4)$ & $6(7)$ & $2(6)$ & $3(7)$ \\
\hline Charcoal & $11(10)$ & $7(10)$ & 8 (13) & $8(7)$ & 6 (TNC) & $7(7)$ \\
\hline Dacron & $11(10)$ & $9(9)$ & $65(36)$ & $13(8)$ & TNC (TNC) & $14(7)$ \\
\hline
\end{tabular}

TNC = Too numerous to count. 
Table 4 Effect of time and temperature on percentage recovery of $N$ meningitidis from swabs (a) held in transport media, and (b) not held in transport media

\begin{tabular}{|c|c|c|c|c|c|c|}
\hline \multirow[t]{2}{*}{ Swabs } & \multicolumn{2}{|l|}{8 hours } & \multicolumn{2}{|l|}{24 hours } & \multicolumn{2}{|l|}{48 hours } \\
\hline & Room temp & $4^{\circ} \mathrm{C}$ & Room temp & $4^{\circ} \mathrm{C}$ & Room temp & $4^{\circ} \mathrm{C}$ \\
\hline \multicolumn{7}{|l|}{ Swabs held in $T M$} \\
\hline Cotton-wool in Amies' & $1(3)$ & $0(2)$ & $0(4)$ & $1(3)$ & $0(1)$ & $0(1)$ \\
\hline Cotton-wool in charcoal Amies' & $1(2)$ & $3(6)$ & $0(0)$ & $0(1)$ & $0(0)$ & $0(0)$ \\
\hline Dacron in charcoal Amies' & $4(1)$ & $1(4)$ & $1(1)$ & $1(2)$ & $0(0)$ & $0(0)$ \\
\hline Cotton-wool in Pike's & $2(2)$ & $3(3)$ & $1(1)$ & $2(2)$ & $0(0)$ & $1(0)$ \\
\hline Cotton-wool in Stuart's & $0(0)$ & $0(1)$ & $0(0)$ & $0(0)$ & $0(0)$ & $0(0)$ \\
\hline Cotton-wool in silica gel & $0(0)$ & $0(0)$ & $0(0)$ & $0(0)$ & $0(0)$ & $0(0)$ \\
\hline \multicolumn{7}{|l|}{ Swabs not held in TM } \\
\hline Plain & $0(0)$ & $1(0)$ & $0(0)$ & $0(0)$ & $0(0)$ & $0(0)$ \\
\hline Albumen & $0(0)$ & $0(0)$ & $0(0)$ & $0(0)$ & $0(0)$ & $0(0)$ \\
\hline Charcoal & $7(4)$ & $5(8)$ & $0(0)$ & $0(4)$ & $0(0)$ & $0(0)$ \\
\hline Dacron & $4(5)$ & $6(5)$ & $0(4)$ & $10(8)$ & $0(0)$ & $2(2)$ \\
\hline
\end{tabular}

Table 5 Effect of time and temperature on percentage recovery of $H$ influenzae from swabs (a) held in transport media and, (b) not held in transport media

\begin{tabular}{|c|c|c|c|c|c|c|}
\hline \multirow[t]{2}{*}{ Swabs } & \multicolumn{2}{|l|}{8 hours } & \multicolumn{2}{|l|}{24 hours } & \multicolumn{2}{|l|}{48 hours } \\
\hline & Room temp & $4^{\circ} \mathrm{C}$ & Room temp & $4^{\circ} \mathrm{C}$ & Room temp & $4^{\circ} \mathrm{C}$ \\
\hline \multicolumn{7}{|l|}{ Swabs held in $T M$} \\
\hline Cotton-wool in Amies' & $1(3)$ & $2(2)$ & $0(0)$ & $0(0)$ & $0(0)$ & $0(0)$ \\
\hline Cotton-wool in charcoal Amies' & $1(1)$ & ! (1) & $2(1)$ & $2(0)$ & $0(4)$ & $0(0)$ \\
\hline Dacron in charcoal Amies' & $0(3)$ & $0(0)$ & $n(2)$ & $0(4)$ & $0(1)$ & $0(3)$ \\
\hline Cotton-wool in Pike's & $1(0)$ & $2(1)$ & $0(0)$ & $2(2)$ & $0(0)$ & $1(2)$ \\
\hline Cotton-wool in Stuart's & $0(0)$ & $0(0)$ & $0(0)$ & $0(0)$ & $0(0)$ & $0(0)$ \\
\hline Cotton-wool in silica gel & $n(0)$ & $0(0)$ & $0(0)$ & $0(0)$ & $0(0)$ & $0(0)$ \\
\hline \multicolumn{7}{|l|}{ Swabs not held in $T M$} \\
\hline Plain & $0(0)$ & $0(1)$ & $0(0)$ & $0(0)$ & $0(0)$ & $0(0)$ \\
\hline Albumen & $0(1)$ & $3(2)$ & $0(0)$ & $0(0)$ & $0(0)$ & $0(0)$ \\
\hline Charcoal & $0(1)$ & $3(3)$ & $0(0)$ & $0(1)$ & $0(0)$ & $0(0)$ \\
\hline Dacron & $1(1)$ & $2(2)$ & $0(0)$ & $0(0)$ & $0(0)$ & $0(0)$ \\
\hline
\end{tabular}

in the ratio of $3: 1$ and those held in TM in the ratio of $7: 1$. This can be explained by the saliva conferring an extra degree of protection to the organisms and is much closer to in vivo conditions.

Counts were maintained more consistently when swabs were held at $4^{\circ} \mathrm{C}$. In certain instances, particularly with Strep pyogenes, it was clear that multiplication of the organisms took place at room temperature and whereas this may be useful occasionally when identification and preservation of fastidious organisms is required, it must be remembered that other contaminating organisms will also multiply in vivo and may overgrow the organisms responsible for causing the infection.

A feature of this study was the uniformly poor performance of swabs immersed in silica. More often than not, no growth was obtained, and at best only a few colonies were recovered. Taplin and Landsell ${ }^{15}$ recommend the use of silica for streptococcal epidemiological field studies but the results of the present study cannot support such claims. They also used calcium alginate swabs but in a previous Edinburgh study with group B streptococci ${ }^{12}$ these were shown to be unsatisfactory.
It is clear that even the best swabs and swab-TM kits yield only a fraction of the initial inoculum. Caution should therefore be exercised in streptococcal field studies. A negative laboratory report may not be correct if persons who are swabbed are carriers of only small numbers of organisms. It may be that a threshold number is required before any can be recovered on laboratory media.

It is concluded from these studies that the TM examined do not serve any useful function in the isolation of bacteria involved in upper respiratory tract infection, and the use of swabs held in plastic containers is therefore perfectly justifiable. Dacron swabs are good, but acceptable results can also be obtained with the other available swabsplain, albumen or charcoal-coated.

We are considerably indebted to: $\mathrm{Mr} \mathrm{W}$ Adams, Computing and Statistics Group, University of Edinburgh, for statistical analyses; Exogen Ltd, Clydebank, Glasgow, and Medical Wire and Equipment Co, Corsham, Wiltshire, for supplying swabs and swab-transport media kits. Financial aid from the following sources is gratefully acknowledged: 
the Scottish Home and Health Department (K/MRS/ 50/C120); the Scottish Hospitals Endowment Research Trust (HERT 493 and HERT 585); Abbott Laboratories Ltd and ER Squibb and Sons.

\section{References}

1 Pollock MR. Unsaturated fatty acids in cotton-wool plugs. Nature 1948;161:853.

${ }^{2}$ Mair NS, McSwiggan DA. Antibacterial bacteriological swabs. Br Med J 1965;ii:230.

${ }^{3}$ Rubbo SD, Benjamin M. Some observations on survival of pathogenic bacteria on cotton-wool swabs: development of a new type of swab. Br Med J 1951 ;i:983-7.

4 Bartlett DI, Hughes MH. Bacteriological swabs. Br Med J 1969;iii:451-3.

5 Ross PW. The isolation of Streptococcus pyogenes from throat swabs. J Med Microbiol 1977;10:69-76.

- Hollinger NF, Rantz L. In pursuit of the streptococcus: newer techniques for their recovery and identification, and clinical implications. Pediatrics 1959;24:1112-7.

${ }^{7}$ Ellner PD, Ellner CJ. Survival of bacteria on swabs. J Bacteriol 1966;91:905-6.

${ }^{8}$ Amies CR. A modified formula for the preparation of Stuart's transport medium. Can J Publ HIth 1967;58: 296-300.
9 Pike RM. The isolation of haemolytic streptococci from throat swabs: experiments with sodium azide and crystal violet in nutrient broth. Am J Hyg 1945;41:211-20.

${ }^{10}$ Stuart RD. Transport problems in public health bacteriology. The use of transport media and other devices to maintain the viability of bacteria in specimens. Can J Publ Hlth 1956;47:114-22.

11 Ross PW, Lough H. Survival of upper respiratory tract bacteria on cotton-wool swabs. J Clin Pathol 1978;31: 430-3.

12 Cumming CG, Ross PW. Evaluation of bacteriological swabs and transport media in the recovery of group B streptococci on laboratory media. J Clin Pathol 1979; 32:1066-9.

${ }^{13}$ Ross PW. Throat swabs and swabbing technique. Practitioner 1971;207:791-6.

14 Collee JG, Watt B, Brown R, Johnstone S. The recovery of anaerobic bacteria from swabs. J Hyg 1974;72:339-47.

15 Taplin D, Landsell L. Value of desiccated swabs for streptococcal epidemiology in the field. Appl Microbiol $1973 ; 25: 135-8$.

Requests for reprints to: Dr PW Ross, Department of Bacteriology, University Medical School, Teviot Place, Edinburgh EH8 9AG, Scotland. 